\title{
Authentic leadership as a source of optimism, trust in the organisation and work engagement in the public health care sector
}

\begin{tabular}{|c|c|}
\hline \multicolumn{2}{|c|}{$\begin{array}{l}\text { Authors: } \\
\text { Frederick W. Stander } \\
\text { Leon T. de Beer }{ }^{2} \\
\text { Marius W. Stander }{ }^{1}\end{array}$} \\
\hline $\begin{array}{l}\text { Affiliations: } \\
{ }^{1} \text { Optentia Res } \\
\text { Area, North- } \\
\text { Vaal Triangle } \\
\text { Africa }\end{array}$ & $\begin{array}{l}\text { earch Focus } \\
\text { Jest University, } \\
\text { Campus, South }\end{array}$ \\
\hline $\begin{array}{l}{ }^{2} \text { WorkWell Re } \\
\text { North-West U } \\
\text { Potchefstroon } \\
\text { South Africa }\end{array}$ & $\begin{array}{l}\text { search Unit, } \\
\text { niversity, } \\
\text { Campus, }\end{array}$ \\
\hline $\begin{array}{l}\text { Corresponden } \\
\text { Frederick Stan }\end{array}$ & $\begin{array}{l}\text { ice to: } \\
\text { der }\end{array}$ \\
\hline $\begin{array}{l}\text { Email: } \\
\text { ederick.stand }\end{array}$ & er@nwu.ac.za \\
\hline $\begin{array}{l}\text { Postal addres } \\
\text { PO Box } 1174, \\
1900 \text {, South A }\end{array}$ & $\begin{array}{l}\text { S: } \\
\text { Vanderbijlpark } \\
\text { frica }\end{array}$ \\
\hline $\begin{array}{l}\text { Dates: } \\
\text { Received: } 07 \text { [ } \\
\text { Accepted: } 07 \\
\text { Published: } 03\end{array}$ & $\begin{array}{l}\text { Apr. } 2014 \\
\text { June } 2015 \\
\text { Jut5 }\end{array}$ \\
\hline $\begin{array}{l}\text { How to cite th } \\
\text { Stander, F.W., } \\
\text { \& Stander, M. } \\
\text { Authentic leac } \\
\text { source of opti } \\
\text { in the organis } \\
\text { work engagen } \\
\text { public health } \\
\text { Journal of Hur } \\
\text { Management } \\
\text { Menslikehulpk } \\
\text { 13(1), Art. \#67 } \\
\text { http://dx.doi. } \\
\text { sajhrm.v13i1. }\end{array}$ & $\begin{array}{l}\text { lis article: } \\
\text { De Beer, L.T., } \\
\text { W. (2015). } \\
\text { dership as a } \\
\text { mism, trust } \\
\text { ation and } \\
\text { tent in the } \\
\text { care sector. SA } \\
\text { nan Resource } \\
\text { SA Tydskrif vir } \\
\text { ronbestuur, } \\
5,12 \text { pages. } \\
\text { org/10.4102/ } \\
575\end{array}$ \\
\hline $\begin{array}{l}\text { Copyright: } \\
\text { (C) 2015. The A } \\
\text { Licensee: AOS } \\
\text { OpenJournals } \\
\text { licensed unde } \\
\text { Commons Att } \\
\text { License. }\end{array}$ & $\begin{array}{l}\text { Authors. } \\
\text { IS } \\
\text { This work is } \\
r \text { the Creative } \\
\text { ribution }\end{array}$ \\
\hline 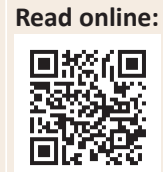 & $\begin{array}{l}\text { Scan this QR } \\
\text { code with your } \\
\text { smart phone or } \\
\text { mobile device } \\
\text { to read online. }\end{array}$ \\
\hline
\end{tabular}

Authors:

Frederick W. Stander

Affiliations:

${ }^{1}$ Optentia Research Focus Area, North-West University,

Vaal Triangle Campus, Sout

Potchefstroom Campus,

South Africa

Correspondence to:

Email:

Postal address:

PO Box 1174, Vanderbijlpark

Accepted: 07 Apr. 2015

Stander, F.W., De Beer, L.T.

source of optimism, trust

in the organisation and

work engagement in the

public health care sector. $S A$

Management/SA Tydskrif vir

Menslikehulpbronbestuur,

1), Art. \#675, 12 pages.

\section{Copyright:}

(C) 2015 . The Authors.

OpenJournals. This work is

licensed under the Creative

Commons Attribution

License.

to read online.
Orientation: The orientation of this study is towards authentic leadership (AL) and its influence on optimism, trust in the organisation and work engagement of employees in the public health care sector.

Research purpose: The objectives of this study were to determine whether the leadership style of AL could predict optimism, trust in the organisation and work engagement amongst a large sample of employees from various functions in public hospitals and clinics in Gauteng and to establish whether optimism and trust in the organisation could mediate the relationship between AL and work engagement.

Research approach, design and method: A convenience sample of 633 public health employees from various functions within 27 public hospitals and clinics in the province was used in this research. A cross-sectional research design was implemented. Structural equation modelling was utilised to investigate the Authentic Leadership Inventory (ALI), and the validity and fit of the measurement model, to position AL as a job resource within the nomological net and to test its mediating effects.

Main findings: The statistical analysis revealed that AL was a significant predictor of optimism and trust in the organisation and that optimism and trust in the organisation mediated the relationship between AL and work engagement.

Practical/managerial implications: The research results suggested that organisations in the public health care sector should encourage their managers to adopt a more authentic leadership style. This will lead to higher levels of optimism, trust in the organisation and eventually work engagement. This will greatly assist employees in the domain of public health care to manage their demanding working environment.

Contribution: This study provides evidence that the ALI can be used reliably within the South African context and specifically within the public health care sector. It further substantiates for the implementation of AL as a leadership style in the South African public health care sector, supporting work that has been done internationally in health care where AL has been associated with a number of positive outcomes. Finally, the study puts forward two practical suggestions, on both an individual and an organisational level, to facilitate a culture in which AL can be translated more effectively into an engaged workforce.

\section{Introduction}

In a significant strategic mission statement, the Department of Health (2011) in South Africa recently articulated a renewed focus on effective leadership as a vocal point of a government function that fulfils a critical role in the country's development. The Health Systems Trust (2013) describes the public health care sector as a major pillar in the country's democratic societal foundation. The provision of basic health care services is a crucial part of a prospering and flourishing society and provides one of the fundamental prerequisites for a civilisation in which equity prevails (Harrison, 2009). In South Africa, access to primary health care is a fundamental human right. This being said, the public health care sector has been plagued by a number of very pressing challenges. These include difficulty in implementing institutional policies that direct the public health care sector (Pillay, 2009), lack of and ill distribution of resources (Christian \& Crisp, 2012), a national disease burden that is estimated to be four times worse than in developed countries (Department of Health, 2011) and a workforce that is continuously migrating to the private health care sector where perceived resources and working environment are considered more favourable (Ashmore, 2013). 
In the National Department of Health (2013) annual report, the minister outlines that glaring differences still exist between the public and private health care sectors, specifically in access and quality of care, and states that this is convoluted by the country's disease affliction (particularly through HIV and/ or AIDS and TB), child and maternal morbidity, lifestyles of certain communities and high occurrence of trauma-related incidents across the entire country and particularly in areas where private health care is not affordable to people. The burden on the South African public health care sector is significant. Of the entire population, $83 \%$ of people receive all medical care in this domain (Blecher, Kollipara, DeJager \& Zulu, 2011). Because basic primary health care in the public sector is available at no charge, very little funding outside of government budget is available to amply equip the sector with resources (Sanders \& Chopra, 2006). The demand for public health care services has also been immense and continues to significantly surpass supply. For example, according to the Health Systems Trust (2011), in the public health care sector, only 2.2 usable beds are available per 1000 members of the population.

This highly complex and severely pressured sector, where a lack of resources and highly overburdening demand for services have been prevalent, has clearly manifested in the form of symptoms amongst its entire workforce. George, Atujuna and Gow (2013), for example, state that employees in the public health care sector have felt totally overwhelmed by the enormity of the task facing them on a daily basis and have negatively related to the pressures delivered through a large portion of the population who are in need of quality health care but cannot afford private care. Von Holdt and Murphy (2006) comment that public health care workers in South Africa experience severe stress and have reported total exhaustion. Drastic measures are required to equip public health care workers to effectively deal with a highly challenging work environment, to uphold levels of wellbeing amongst these individuals and to counter the high rate of turnover of these employees who are leaving the sector due to an environment that becomes too overburdening (George, Gow \& Bachoo, 2013).

The need for these measures has been recognised by the Department of Health, who have introduced the National Core Standards for Health Establishments in South Africa (Department of Health, 2011), in which it adopts 'leadership' (domain 5) very purposefully as a critical component of its overarching strategy to navigate the challenges of public health care and provide for a healthy workforce who are able to be actively engaged and effective within this environment. The drive for purposeful leadership interventions has not only been recognised by the Department of Health in South Africa, but has long been advocated in academic literature as well. For example, Gilson and Daire (2011) state that:

leadership is a necessary element of strong health systems, and so it is vital that SA nurtures and sustains leaders who can work strategically within their complex environments to develop a rights-based health system that promotes health equity. (p. 69)
Bamford, Wong and Laschinger (2013) further highlight the importance of strong leadership to build and sustain healthier work environments to deal with the demands in the health care profession. Although the concept of leadership has been widely introduced through the policy direction of the Department of Health, and literature has been published championing a stronger emphasis on leadership within public health care, very little empirical work exists that explore the value of specific leadership styles in this sector. This represents a major research gap, not only from a scientific perspective but equally so from the pragmatic view of assisting the South African national government in understanding which approaches could be effective in nurturing an engaged workforce within a work environment in public health care that is going to remain highly demanding. This article proposes the leadership style of authentic leadership (AL) as a pragmatic approach to be adopted in the public health care sector as a means of creating an engaged workforce. Laschinger, Wong and Grau (2013) state that few empirical studies link authentic leadership with work attitudes and outcomes in health care.

\section{Literature review}

\section{Authentic leadership as a leadership style in the public health care sector}

AL refers to a leadership style that includes positive leader capacities and a mature organisational leadership culture (Luthans \& Avolio, 2003). This forms the basis of the concept of AL as investigated in this paper. As a concept it proposes high levels of self-awareness and positive behaviours on the side of both leader and follower (Ilies, Morgeson \& Nahrgang, 2005). It is based on the construct of authenticity, which is described by Kernis (2003) as being absolutely true to one's own being in all daily interactions. The authentic leader displays behaviours of inspiring others, motivating followers, stimulating on an intellectual level and giving individualised attention to followers (Neider \& Schriesheim, 2011). In this sense the authentic leader acts as a 'moral agent' who introduces transformational leadership to the organisation in which they function (Bass \& Steidlmeier, 1999). AL has been proven to be a valuable approach in a number of organisational studies. For example, Peus, Wesche, Streicher, Braun and Frey (2012) found AL to be a predictor of organisational commitment, extra effort and team effectiveness in a sample of business and research organisations in Germany. In a sample of employees from telecommunications firms in China, AL was positively related to organisational citizenship and work engagement (Walumbwa, Wang, Wang, Schaubroeck \& Avolio, 2010).

AL comprises four constructs (Walumbwa, Avolio, Gardner, Wernsing \& Peterson, 2008). Self-awareness refers to the ability to make sense of one's perceived reality and understand one's strengths and weaknesses. Laschinger and Fida, (2014) postulate that authentic leaders have a stable sense of self knowledge. Relational transparency talks to presenting the true and core self to other people. Balanced processing refers to objectively analysing all sets of information about a particular 
scenario before coming to a particular conclusion. Internalised moral perspective refers to the ability of self-regulation as to hold a firm moral position, internally inclined, that can withstand both societal and group pressures. The four AL constructs are measured through the Authentic Leadership Inventory (ALI), developed by Neider and Schriesheim (2011). The measure assesses the extent to which a group of followers perceive their leader to display the behaviours associated with the four AL constructs. It has been proven to be reliable by Neider and Schriesheim.

Although the potential value of adopting an AL approach in an organisation has been proven in a number of studies, very little empirical work has been done within South Africa and no studies have evaluated the positive effect that AL could have as a leadership style within the public health care sector in this country. This is despite international work within broader health care that has linked AL to trust and job performance amongst a sample of Canadian nurses, pharmacists and physicians (Wong \& Cummings, 2009), to work engagement amongst a sample of registered nurses in the province of Ontario in Canada (Bamford et al., 2013), to job satisfaction amongst a sample of UK nurses (Leigh, 2013) and to burnout, mental health and job satisfaction amongst new nurses (Laschinger \& Fida, 2014). This represents an important research gap in the South African literature. It is important to investigate the application of AL within South African organisations and, more so, it could be fruitful to apply this leadership style within the domain of the public health care sector. Based on the literature and empirical work done internationally it is possible to postulate:

- Hypothesis 1: The ALI will be reliable for use in a South African context.

- Hypothesis 2: The ALI holds a four-factor structure in a sample of employees from the public health care sector.

\section{Positioning authentic leadership as a job resource in relation to the nomological network}

This article postulates that, in the context of the public health care sector in South Africa, the leadership style of AL will act as a job resource in line with the job demands-resources (JD-R) model. The JD-R model is a strongly established theory within industrial psychology. It holds that all job roles inherently comprise a set of demands and resources (Bakker, Demerouti, Taris, Schaufeli \& Schreurs, 2003). Whilst demands constitute those elements of the job that require psychological, physical, social or organisational strain, job resources include capitals that assist individuals to successfully accomplish tasks and be more effective in their job role (Bakker \& Demerouti, 2007). Job resources effectively mitigate against the effects of job demands and include physical, social or organisational elements of a job role that allow the role incumbent to more readily achieve desired personal and organisational outcomes (Bakker \& Demerouti, 2008; Xanthopoulou, Bakker, Demerouti \& Schaufeli, 2009). It is argued here that the leadership style of AL can be postulated as a job resource as it has been effectively proven to navigate various challenging organisational cultures and to be associated with desired organisational outcomes. Examples of this include Wong and Cummings (2009), who have found the leadership style of AL predicted job performance amongst a sample of Canadian nurses, as well as Peus et al. (2012), who have established a correlation between AL and team effectiveness amongst German employees working in research industries.

To substantiate the case for postulating AL as a job resource, it is important to investigate its correlation with other, established job resources within the theoretical framework of the nomological net. In this article, AL is compared to the job resource of communication and relationships with colleagues. According to Van Veldhoven, Meijman, Broersen and Fortuin (2002), communication as a resource entails whether an individual has a clear understanding of how processes, decision-making and important procedures work within their organisation. Relationship with colleagues refers to whether an individual gets along with, feels comfortable with and can count on colleagues for support in their job role. Both communication and relationship with colleagues are measured through the questionnaire on experience and assessment of work, developed in the Netherlands and known by its abbreviation VBBA (Van Veldhoven, Meijman, Broersen, \& Fortuin, 1997):

- Hypothesis 3: Authentic leadership can be postulated as a job resource in the nomological net in relation to communication and relationship with colleagues.

\section{Authentic leadership as a predictor of positive personal and work-related outcomes}

Laschinger and Fida (2014) found that AL and psychological capital (PsyCap) have an impact on personal and jobrelated outcomes in the nursing environment. Adopting the point of departure that AL is a job resource in relation to other established job resources in the nomological net, as outlined above, it becomes possible to postulate that this leadership style may lead to positive personal and workrelated outcomes. This view is validated when considering the theoretical description, which holds that job resources assists individuals in achieving both personal and workrelated goals (Xanthopoulou et al., 2009). In this article, the potential of AL to predict the personal outcome of optimism, and the work-related outcome of trust in the organisation, is investigated.

Optimism is a construct that forms part of the collective term psychological capital (PsyCap) as described by Luthans and Youssef (2004). PsyCap can be described as a 'an individual's positive psychological state of development, characterised by: (1) having confidence (self-efficacy) to take on and put in the necessary effort to succeed at challenging tasks, (2) making a positive attribution (optimism) about succeeding now and in the future, (3) persevering towards goals, and when necessary, redirecting paths to goals (hope) in order to succeed and (4) when beset by problems and adversity, sustaining and bouncing back and even beyond (resiliency) to attain success' (Luthans, Youssef \& Avolio, 2007, p. 10). 
Although a fairly new concept within psychology, PsyCap has effectively been proven as a personal resource that assists individuals in attaining goals (Luthans, Avolio, Avey \& Norman, 2007). Laschinger and Fida (2014) are of the opinion that PsyCap, as a personal strength may enable new graduate nurses to proactively manage stressful challenges. The PsyCap constructs have been established as valid in a South African sample by Görgens-Ekermans and Herbert (2013) through a thorough validation study conducted within the construction industry. It will hence be interesting to further scrutinise this finding by investigating the properties of these constructs within the public health care sector.

Optimism has been referred to by Luthans (2002) as comprising both positive emotion and motivation in life. It refers to an individual's ability and positive psychological developmental state towards having an ascription of being successful, now and in the future (Luthans, Avolio, Avey \& Norman, 2007). A number of studies have correlated the leadership style of AL with PsyCap. For example, Clapp-Smith, Vogelgesang and Avey (2009) established correlation between AL and PsyCap in a sample of employees from the retail industry. Rego, Sousa, Marques and Cunha (2012) established that AL promoted PsyCap amongst employees from 33 different organisations in Portugal. This is because AL is 'a pattern of leader behaviour that draws upon and promotes both positive psychological capacities and a positive ethical culture, to foster greater self-awareness, an internalized moral perspective, balanced processing of information, and relational transparency on the part of leaders working with followers, fostering positive self-development' (Walumbwa et al., 2008, p. 94). The leadership style of AL should also aid the highly demanding public health care environment to promote levels of optimism amongst staff in a process of positive organisational behaviour, considering its value, which has been established through studies in other contexts:

- Hypothesis 4: Authentic leadership will promote optimism amongst employees in the public health care sector.

Following the above hypothesis, this article postulates that AL will also predict positive work-related outcomes, in particular the outcome of trust in the organisation, which is the particular focus of this study. Trust in the organisation can be described as a sense of confidence in and support towards one's employer (Gilbert \& Tang, 1998). It is the conviction that an individual holds that the organisation that employs them has their best interest at heart (Gilbert \& Tang, 1998). Bromiley and Cummings (1996) hold that, when employees have trust in their organisation, those employees will invest energy and effort to ensure that organisational objectives are successfully attained. Trust in the organisation has been associated with various positive outcomes. This includes work engagement (Gillis, 2003), knowledge sharing amongst team members in organisations (Ferres, Connell \& Travaglione, 2005), effective leadership (Joseph \& Winston, 2005) and employee performance (Paliszkiewicz \& Koohang, 2013). A culture of trust in the organisation is thus a highly sought-after organisational state.
It is postulated here that the leadership style of AL will foster greater trust in the organisation, within the domain of the public health care sector. Trust in the organisation, in this instance, is selected due to Luthans and Avolio's (2003) observation that AL comprises authenticity, embedded into a particular organisational culture. This is because AL constitutes authenticity and positive empowering behaviours which will render employees more able and willing to trust their employers. It supports the work of Bono and Judge (2003) who have outlined the relevance of social and personal identification as part of the leadership process towards attaining positive outcomes. The rationale for this is further supported by Avolio, Gardner, Walumbwa, Luthans and May (2004), who stipulate that AL allows a realistic social interaction between leader and follower in a culture that supports open communication and free sharing of information. This manifests in a culture of trust within the organisation, as the authentic nature of the leadership style ensures transparency and the sense that the organisation, through the extension of its leadership, has the best interests of employees in mind (Gardner, Avolio, Luthans, May \& Walumbwa, 2005).

From the perspective of this article, trust in the 'organisation' is here represented as trust in the public health department, which employs the participants of this study through various hospitals and clinics. In a number of studies, AL has been proven as a leadership style that can harness trust in the organisation, particularly in the health care environment. For example, Wong and Cummings (2009) established that AL predicted trust in the organisation amongst a sample of both clinical care and non-clinical (support) staff of Canadian health care facilities. This is significant in the context of this study, where the public health care sector as a whole was considered, including both medical practitioners and support staff. In further studies, AL was proven to be a source of trust in the organisation in a large sample of Malaysian employees in the banking sector (Hassan \& Ahmed, 2011) and a large sample of employees working in the financial services industry (Walumbwa, Luthans, Avey \& Oke, 2009):

- Hypothesis 5: Authentic leadership will promote trust in the organisation in the public health care sector.

$\mathrm{AL}$ is further investigated in this article as being able to predict the positive work-related outcome of work engagement. Work engagement is defined by Schaufeli and Bakker (2004, p. 295) as a 'positive, fulfilling, work-related state of mind characterised by vigour, dedication, and absorption'. Of late, only vigour and dedication have been included as core dimensions of work engagement (Stander \& Mostert, 2013). Vigour describes an individual's continued positive feelings towards elements of their job role, whereas dedication constitutes an individual's pride in their job (Schaufeli, Salanova, González-Romá \& Bakker, 2002). Work engagement is a highly researched and well-established topic in the literature. It has been associated with such outcomes as motivation amongst employees (Sonnentag, 2003), organisational commitment (Demerouti, Bakker, De 
Jonge, Janssen \& Schaufeli, 2001) and increased performance (Bakker, 2011). An engaged workforce is a highly soughtafter state of any organisation, as an engaged employee is fully connected to their job role and can thus fulfil such role with higher efficiency and effectiveness (Bakker, 2011).

In the public health care sector in South Africa, an engaged workforce is critical to navigate the challenges associated with a segment that is overburdened by demands and a lack of resources. It is therefore crucial to investigate means as to which work engagement can be fostered amongst both medical and support staff in this sector and AL as a leadership style is proposed here as a means of achieving this. It has been proven that AL can facilitate work engagement amongst employees. This has been established by Wang and Hsieh (2013) in a large sample of employees from manufacturing companies in Taiwan, by Walumbwa et al. (2010) amongst employees from the telecommunications industry in China, by Bamford et al., (2013) with a group of registered nurses and by Brown (2014) amongst a sample of athletes in the United States. Based on this the following hypothesis is postulated:

- Hypothesis 6: Authentic leadership will promote work engagement amongst employees in the public health care sector.

\section{Optimism and trust in the organisation as mediators in the relationship between authentic leadership and work engagement}

Following the postulation that AL will predict both positive personal and work-related outcomes in the public health care sector, this article will further investigate the indirect relationship that two of the variables have on the relationship between AL and work engagement, that is, it will investigate whether favourable personal and work contexts can potentially strengthen the effect of a AL leadership style on the level of work engagement of employees in this sector.

Firstly, from a personal resource perspective, the potential mediating effects of optimism is explored in this article. It is possible to predict that optimism will mediate the relationship between AL and work engagement, because optimism forms part of the PsyCap constructs and should therefore assist employees in the public health care sector to translate the job resources available to them into favourable outcomes. This is because PsyCap, and optimism by extension, form part of an individual's personal resources and renders that person in a state of positive psychological development (Luthans, Avolio, Avey \& Norman, 2007). Optimism has been proven to be a mediator between various job resources and the outcome of work engagement. Xanthopoulou et al. (2009) established that optimism mediated the relationship between the job resources of autonomy, coaching and team culture and work engagement, in a sample of employees from Greek restaurants. In a study by Tims, Bakker and Xanthopoulou (2011) optimism fully mediated between a transformational leadership style and work engagement in a large sample of consultants from two organisations in the Netherlands. It is thus possible to argue that a positive leadership style will

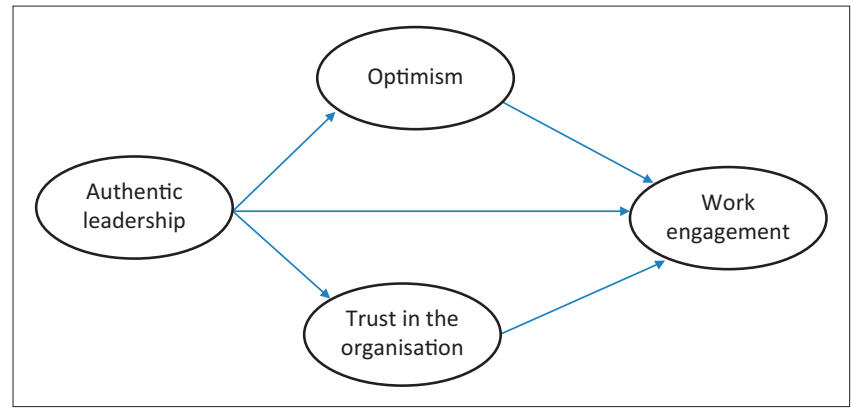

FIGURE 1: The research model.

be mediated towards work engagement by a workforce that holds high levels of optimism. This article argues that an individual who is employed in the public health care sector and holds the optimistic view that they will be successful in their endeavours, now and in the future, will be more amply equipped to translate the positive leadership style observed by them through an AL approach into a state of work engagement.

Furthering the research, it is also postulated here that favourable work-related culture of trust in the organisation will mediate between AL and work engagement. Trust in the organisation creates a culture in which employees believe their employers have their best interest at heart and they will therefore be more willing to invest a full effort to attain organisational goals, within the positive framework provided through an AL leadership style (Gilbert \& Tang, 1998). Aryee, Budhwar and Chen (2002) established that trust in the organisation mediated between perceived organisational justice and job satisfaction of employees in the public sector in India. Pertaining specifically to work engagement, Acosta, Salanova and Llorens (2011) recognised a full mediating effect of trust in the organisation in the relationship between healthy organisational practices and work engagement of employees from small and medium-sized enterprises in Spain. This article will explore the possible mediating effect that trust in the organisation will have between AL and work engagement in the public health care sector in South Africa:

- Hypothesis 7a: Optimism will mediate the relationship between authentic leadership and work engagement

- Hypothesis 7b: Trust in the organisation will mediate the relationship between authentic leadership and work engagement

Figure 1 presents the research model.

\section{Method}

\section{Research approach}

To investigate this research a quantitative approach was used. Quantitative approaches are usually more structured and collect larger samples of data (Struwig \& Stead, 2001). More specifically, a survey design was used to collect crosssectional data. Cross-sectional data means that the data were collected at one point in time (Salkind, 2009). 


\section{Participants and procedure}

The total sample $(N=633)$ had an average age of 42.44 years $(\mathrm{SD}=12.27)$ and was drawn from 27 public hospitals and clinics in the province. The majority of the sample was female $(79.6 \%)$. The home languages with the most participation were Sesotho $(n=263 ; 44.6 \%)$ and isiZulu $(n=113 ; 19.2 \%)$. Furthermore, participation from the English $(n=39)$, Afrikaans $(n=42)$, Setswana $(n=43)$, and isiXhosa $(n=40)$ language groups were quite similar. The majority of the sample consisted of black people $(n=522 ; 87.9 \%)$ followed by a minority of white participants $(n=49 ; 8.2 \%)$ as the second largest group. This demographic composition is representative of the South African public health sector workforce. In terms of qualifications, 156 participants (29.8\%) had a higher senior certificate, $202(38.5 \%)$ had a diploma or tertiary certificate, $122(23.3 \%)$ had a degree and $44(8.4 \%)$ had a postgraduate degree. With regard to function, 94 (7.41\%) of the sample indicated management, 65 (12.04\%) indicated specialist, 106 (19.63\%) indicated administrative and 275 (50.92\%) of the sample indicated other.

This research was conducted as part of a broader project with the public health department in Gauteng, aimed at studying the work-related experiences and well-being of employees in the public health care sector. The research was conducted through a gatekeeper appointed by the department, after a rigorous process of application for ethical clearance was done so as to ensure clearance from the department. The research project leader engaged the respondents through the gatekeeper and distributed the research questionnaires to respondents in pre-arranged time-slots, on site at the hospitals and clinics, in pre-arranged venues, according to department and function. The research project leader was accompanied by research assistants during the data collection process. The project leader explained the aim, nature and detail of the research to the participants, emphasising the voluntary nature of the procedure. Participants were also briefed on the confidential nature of their responses, which were to be captured only for research purposes. Participants were allowed to ask questions and the project leader was available throughout the process to answer any enquiries the respondents may have had. Although it was reasonably foreseen that the research project presented low risk, the added advantage was that the research project leader is a qualified industrial psychologist and could thus adequately attend to any discomfort participants may have experienced during the research process. Completed questionnaires were collected by the research project leader and stored for the purposes of safekeeping in a secure storeroom on a university premises. An information letter was also distributed, providing participants with the contact details of the project leader, should any queries arise.

\section{Measuring instruments}

A biographical questionnaire was used to obtain information concerning the biographical features of participants (e.g. age, gender, level of qualification and home language). The subsequent measuring instruments were administered.
Authentic leadership: AL was measured through the ALI (Neider \& Schriesheim, 2011). The ALI contains 14 items. It is scored on a five-point Likert scale on which responses vary from 1 (disagree strongly) to 5 (agree strongly). Example items are 'My leader solicits feedback for improving their dealings with others' and 'My leader encourages others to voice opposing points of view'. Cronbach's alpha coefficients indicated that the scale in general is reliable $(\alpha=0.74-0.85$; Neider \& Schriesheim, 2011). During the briefing of the participants, it was explained that 'my leader' in this context refers to the direct line manager of the employee.

Job resources: Both the job resources of relationship with colleagues and communication were measured by the questionnaire on experience and assessment of work, the VBBA (Van Veldhoven et al., 1997). The VBBA is scored on a four-point frequency rating scale, ranging from 0 (never) to 3 (always). Van Veldhoven et al. (2002) have found sufficient levels of internal consistency ( $\alpha=0.87$ for relationship with colleagues and $\alpha=0.79$ for communication). Relationship with colleagues was measured through six items. An example item is 'Do you get on well with your colleagues?'. Communication was measured through four items, an example of which is the item 'In your work, do you have access to sufficient data and information?'.

Optimism: The PsyCap construct of optimism was measured through the specific optimism items on the 12-item PsyCap Questionnaire (PCQ 12; Luthans, Avolio, Avey \& Norman, 2007). As part of the overall PCQ 12, optimism is measured through three items. The items of this measure are scored on a six-point Likert scale ranging from 1 (strongly disagree) to 6 (strongly agree). An example of an optimism item is 'I always look on the bright side of things regarding my job'. The Cronbach's alpha coefficient indicated sufficient reliability for this instrument $(\alpha=0.93$; Norman, Avolio \& Luthans, 2010).

Trust in the organisation: The dimension trust in the organisation was measured through the Workplace Trust Survey (WTS; Ferres \& Travaglione, 2003). The WTS comprises nine items for its trust in the organisation dimension. Responses are logged on a seven-point Likert scale ranging from 1 (strongly disagree) to 7 (strongly agree). An example item is 'I think that this organisation provides a supportive environment'. Sufficient levels of internal consistency $(\alpha=0.95)$ have been reported for this measure (Ferres \& Travaglione, 2003).

Work engagement: Work engagement was measured through the Utrecht Work Engagement Scale (UWES; Schaufeli et al., 2002), through eight items in this particular study. Responses are recorded on a seven-point frequency scale ranging from 0 (never) to 6 (daily). Example items are 'At my work I always persevere, even when things do not go well' (dedication) and 'At my job, I feel strong and vigorous' (vigour). Alpha coefficients of the UWES have ranged from 0.68 to 0.91 (Schaufeli et al., 2002). In the South African 
context, Storm and Rothmann (2003) established Cronbach's alpha coefficients of 0.78 for vigour and 0.89 for dedication.

\section{Statistical analysis}

Latent variables were constructed with structural equation modelling methods in Mplus 7.2 (Muthén \& Muthén, 2014). No item parcelling methods were used and each item was therefore an indicator of the latent variable specified. Moreover, due to the categorical nature of the data (i.e. Likert scale-type data), the weighted least squares (mean and variance adjusted) estimation method was implemented, as per the default option in Mplus as it is a more accurate method (Rhemtulla, Brosseau-Liard \& Savalei, 2012). This is done by estimating thresholds for the response categories, as the distance between, for example, 'never' and 'seldom' is not the same as between 'seldom' and 'always' (cf. Liang \& Yang, 2014). First a measurement model was specified (i.e. confirmatory factor analysis). Then, regression coefficients were added to the model to constitute the structural model. The following fit indices were considered for model fit in the measurement and structural models: comparative fit index (CFI) and Tucker-Lewis index (TLI) with acceptable values above 0.90 and the root mean square error of approximation (RMSEA), the value of which should ideally be below 0.08 (Van de Schoot, Lugtig \& Hox, 2012). Furthermore, bootstrapping methods were implemented with a request for 5000 resampling draws in order to ascertain the possibility of indirect effects in the research model with confidence intervals at the 95\% level of confidence (Rucker, Preacher, Tormala \& Petty, 2011). Correlation coefficients were also considered with practical significance $(r)$ being considered at 0.30 or higher for a medium effect and 0.50 or higher for a large effect (Cohen, 1988). Overall statistical significance for the research was set at the $99 \%$ level (i.e. $p \leq 0.01$ ).

\section{Results}

\section{Measurement model}

As the sample data was categorical in nature and the weighted least squares methodology was implemented, it was not possible to directly compete non-nested measurement models with chi-square difference testing. Additionally, it should be stated that authentic leadership as a latent variable could only be estimated as one factor; any other permutation (fourfactor model or second-order factor model) resulted in model estimation error with a non-positive definite covariance matrix. Confirmatory factor analysis revealed that the overall measurement model, which included all study variables as singular latent variables in one model, was a good fit to the data: the CFI (0.95) and TLI (0.94) were both above the lower bound cut-off point of 0.90 and the RMSEA (0.06) was below the value of 0.08 .

Table 1 presents the factor loadings for the latent variables.

As can be seen from Table 1 the factor loadings of all the items loaded significantly on the corresponding latent factor in the confirmatory factor analysis. The standard errors for each of
TABLE 1: Factor loadings for the latent variables.

\begin{tabular}{|c|c|c|c|c|}
\hline Latent variable & Item & $\begin{array}{l}\text { Standardised } \\
\text { loading }\end{array}$ & $\begin{array}{l}\text { Standard } \\
\text { error }\end{array}$ & $p$-value \\
\hline \multirow[t]{14}{*}{ Authentic Leadership } & AL1 & 0.77 & 0.02 & 0.001 \\
\hline & $\mathrm{AL} 2$ & 0.78 & 0.02 & 0.001 \\
\hline & AL3 & 0.76 & 0.02 & 0.001 \\
\hline & $\mathrm{AL4}$ & 0.76 & 0.02 & 0.001 \\
\hline & AL5 & 0.46 & 0.03 & 0.001 \\
\hline & AL6 & 0.83 & 0.01 & 0.001 \\
\hline & AL7 & 0.79 & 0.02 & 0.001 \\
\hline & AL8 & 0.81 & 0.02 & 0.001 \\
\hline & AL9 & 0.46 & 0.03 & 0.001 \\
\hline & AL10 & 0.81 & 0.01 & 0.001 \\
\hline & AL11 & 0.73 & 0.02 & 0.001 \\
\hline & AL12 & 0.80 & 0.02 & 0.001 \\
\hline & AL13 & 0.72 & 0.02 & 0.001 \\
\hline & AL14 & 0.72 & 0.02 & 0.001 \\
\hline \multirow[t]{4}{*}{ Communication } & COM1 & 0.78 & 0.02 & 0.001 \\
\hline & COM2 & 0.89 & 0.02 & 0.001 \\
\hline & COM3 & 0.89 & 0.02 & 0.001 \\
\hline & COM4 & 0.72 & 0.03 & 0.001 \\
\hline \multirow[t]{6}{*}{ Colleague relationships } & COL1 & 0.65 & 0.04 & 0.001 \\
\hline & $\mathrm{COL} 2$ & 0.64 & 0.04 & 0.001 \\
\hline & COL3 & 0.72 & 0.03 & 0.001 \\
\hline & COL4 & 0.78 & 0.03 & 0.001 \\
\hline & COL5 & 0.83 & 0.02 & 0.001 \\
\hline & COL6 & 0.85 & 0.02 & 0.001 \\
\hline \multirow[t]{3}{*}{ Optimism } & OPT1 & 0.55 & 0.04 & 0.001 \\
\hline & OPT2 & 0.97 & 0.03 & 0.001 \\
\hline & OPT3 & 0.77 & 0.03 & 0.001 \\
\hline \multirow[t]{9}{*}{ Trust in the organisation } & TRUST1 & 0.76 & 0.02 & 0.001 \\
\hline & TRUST2 & 0.75 & 0.02 & 0.001 \\
\hline & TRUST3 & 0.77 & 0.02 & 0.001 \\
\hline & TRUST4 & 0.67 & 0.03 & 0.001 \\
\hline & TRUST5 & 0.81 & 0.02 & 0.001 \\
\hline & TRUST6 & 0.84 & 0.01 & 0.001 \\
\hline & TRUST7 & 0.77 & 0.02 & 0.001 \\
\hline & TRUST8 & 0.73 & 0.02 & 0.001 \\
\hline & TRUST9 & 0.70 & 0.02 & 0.001 \\
\hline \multirow[t]{8}{*}{ Work engagement } & ENG1 & 0.51 & 0.04 & 0.001 \\
\hline & ENG2 & 0.85 & 0.01 & 0.001 \\
\hline & ENG3 & 0.82 & 0.02 & 0.001 \\
\hline & ENG4 & 0.74 & 0.02 & 0.001 \\
\hline & ENG5 & 0.77 & 0.02 & 0.001 \\
\hline & ENG6 & 0.92 & 0.01 & 0.001 \\
\hline & ENG7 & 0.86 & 0.01 & 0.001 \\
\hline & ENG8 & 0.81 & 0.02 & 0.001 \\
\hline
\end{tabular}

Note: All two-tailed $p$ values $\leq 0.001$.

the standardised estimates were small, indicating accuracy in estimation of these values.

Table 2 presents the correlation matrix for the latent variables, including their corresponding alpha and omega reliability coefficients.

The reliability indicators of all the latent variables were acceptable according to the popular guidelines $(\alpha \& \omega \geq$ 0.70). AL was positively correlated with all of the other latent variables with at least a medium practical significant effect, for example with optimism $(r=0.45)$, trust in the organisation $(r=0.68)$, and work engagement $(r=0.42)$. Optimism was practically significantly correlated to work engagement with 
TABLE 2: Correlation matrix for the latent variables.

\begin{tabular}{|c|c|c|c|c|c|c|c|c|}
\hline \multirow[t]{2}{*}{ Variable name } & \multicolumn{2}{|c|}{ Reliabilities } & \multicolumn{6}{|c|}{$r$} \\
\hline & $\alpha$ & $\omega$ & 1 & 2 & 3 & 4 & 5 & 6 \\
\hline Authentic Leadership & 0.93 & 0.93 & 1.00 & - & - & - & - & - \\
\hline Colleague relationships & 0.83 & 0.84 & $0.41 \dagger$ & 1.00 & - & - & - & - \\
\hline Communication & 0.84 & 0.84 & $0.64 \ddagger$ & $0.33 \dagger$ & 1.00 & - & - & - \\
\hline Optimism & 0.74 & 0.75 & $0.45 \dagger$ & 0.18 & 0.29 & 1.00 & - & - \\
\hline Trust in the organisation & 0.88 & 0.90 & $0.68 \%$ & 0.28 & $0.44 \dagger$ & $0.31 \dagger$ & 1.00 & - \\
\hline Work engagement & 0.90 & 0.90 & $0.42 \dagger$ & 0.17 & 0.27 & $0.60 \%$ & $0.50 \dagger$ & 1.00 \\
\hline
\end{tabular}

$\alpha$, alpha coefficient; $\omega$, omega coefficient; $r$, correlation coefficient.

$\dagger$, medium effect; $\$$, large effect.

$p<0.01$

TABLE 3: Regression paths of the research model.

\begin{tabular}{lccc}
\hline Regression relationships & $\begin{array}{c}\text { Standardised } \\
\text { estimate }\end{array}$ & $\begin{array}{c}\text { Standard } \\
\text { error }\end{array}$ & $\boldsymbol{p}$ \\
\hline Authentic leadership $\rightarrow$ Optimism & 0.45 & 0.04 & 0.001 \\
$\begin{array}{l}\text { Authentic leadership } \rightarrow \text { Trust in the } \\
\text { organisation }\end{array}$ & 0.68 & 0.02 & 0.001 \\
$\begin{array}{l}\text { Authentic leadership } \rightarrow \text { Work engagement } \\
\text { Optimism } \rightarrow \text { Work engagement }\end{array}$ & -0.07 & 0.06 & 0.200 \\
$\begin{array}{l}\text { Trust in the organisation } \rightarrow \text { Work } \\
\text { engagement }\end{array}$ & 0.51 & 0.04 & 0.001 \\
\hline
\end{tabular}

Note: All two-tailed $p$-values $\leq 0.01$.

TABLE 4: Indirect effects between authentic leadership and work engagement.

\begin{tabular}{llccc}
\hline Variable & Estimate & $p$ & \multicolumn{2}{c}{$\mathbf{9 5 \%}$ confidence interval } \\
\cline { 4 - 5 } & & & Lower & Upper \\
\hline Optimism & 0.23 & 0.001 & 0.16 & 0.30 \\
Trust in organisation & 0.27 & 0.001 & 0.19 & 0.34 \\
\hline
\end{tabular}

$p<0.001$

a large effect $(r=0.60)$. The correlation between optimism and trust in the organisation was of medium practical significance $(r=0.31)$. Moreover, trust in the organisation and work engagement were also largely practically correlated with each other $(r=0.50)$. Finally, AL was practically significantly correlated with both relationships with colleagues $(r=0.41)$ and communication $(r=0.64)$.

\section{Structural model: Regression results}

Based on the acceptable measurement model, the structural regressions were added to the model as hypothesised from the literature. The structural model also showed acceptable fit to the data $(\mathrm{CFI}=0.92 ; \mathrm{TLI}=0.92 ; \mathrm{RMSEA}=0.07)$.

Table 3 shows that the regression relationships were significant at a level of $p$ less than 0.01 . Authentic leadership positively predicted optimism $(\beta=0.45 ; \mathrm{SE}=0.04 ; p=0.001)$ and trust in the organisation $(\beta=0.68 ; \mathrm{SE}=0.02 ; p=0.001)$, but did not predict work engagement $(\beta=-0.07$; $\mathrm{SE}=0.06$; $p=0.200)$. Optimism $(\beta=0.51 ; \mathrm{SE}=0.04 ; p=0.001)$ and trust in the organisation $(\beta=0.39$; $\mathrm{SE}=0.05 ; p=0.001)$ in turn positively predicted work engagement.

\section{Structural model: Indirect effects}

Due to the significant regression relationships from AL to optimism and trust in the organisation, and their subsequent relationship to work engagement, both potential indirect effects were investigated. Feedback is provided in Table 4.
Results from the bootstrapping resampling implementation revealed that both indirect effects were significant: the relationship from AL to work engagement through optimism (0.23; 95\% CI [0.16, 0.30]; $p \leq 0.001)$ and from AL to work engagement though trust in the organisation $(0.27 ; 95 \% \mathrm{CI}$ $[0.19,0.34] ; p \leq 0.001)$. Therefore, the sum of the indirect effects for the total model was $0.494(p \leq 0.001)$.

\section{Discussion \\ Outline of the results}

The objectives of this study were to determine whether the leadership style of AL could predict optimism, trust in the organisation and work engagement amongst a large sample of employees from various functions in public hospitals and clinics in Gauteng and to establish whether optimism and trust in the organisation could mediate the relationship between AL and work engagement. This was done to generate knowledge and understanding to assist the public health care sector to harness an engaged workforce. This proves particularly relevant in the South African public health care sector, which is characterised by severely demanding working conditions and an overall lack of resources (Christian \& Crisp, 2012). The practical value of this study emerges when considering the clear policy direction of the country's Department of Health, which has indicated through domain 5 of the strategic document known as the National Core Standards for Health Establishments in South Africa (Department of Health, 2011), that 'leadership' would be a key focus area on harnessing an engaged, vigorous workforce that would be able to deal effectively with the burdening environment that is public health care provision. The sector as a whole was considered and therefore both direct health care professionals and support staff were included in the investigation. The structural model under scrutiny in this paper proposed that AL would be an effective leadership style to harness both positive personal and work-related outcomes, specifically optimism, trust in the organisation and work engagement. Based on the theory outlined in the literature study, the authors proposed this structural model as a pragmatic way of dealing with pressing issues in the South African public health care sector, such as migration from employees to the private health care sector (George et al., 2013), assisting the workforce in the public health care sector to more effectively deal with stress (Von Holdt \& Murphy, 2006) and assisting employees in the sector 
to more effectively negotiate the various demands they will clearly continue to face on a daily basis (George et al., 2013).

The point of departure was to first establish whether AL as a concept could be applied reliably to a South African sample and, more specifically, to the South African public health care sector. AL is measured through the ALI, based on the four AL constructs identified by Walumbwa et al. (2008): known as self-awareness, relational transparency, balanced processing and internalised moral perspective. Although AL as a concept has been proven as a leadership style that could unlock great value in health care internationally, in such studies as Wong and Cummings (2009), who established AL to predict work performance amongst Canadian health care practitioners, and Leigh (2013), who found AL led to job satisfaction amongst nurses from the UK, it has largely been un-researched in South Africa; no studies have investigated its potential value and application in public health. This represented a major research gap. Through psychometric evaluation, the authors established that the ALI was reliable for use in a South African context, through both alpha and omega reliability coefficients, rendering Hypothesis 1 of this article as accurate. After this was established, the next step was investigation of the factor structure of the ALI. Based on the theoretical foundations AL presented by Walumbwa et al. (2008) and various psychometric studies by such authors as Neider and Schriesheim (2011), the authors postulated through Hypothesis 2 that the ALI would also hold a fourfactor structure in the South African context. Competing measurement models were tested through a process of structural equation modelling and the traditional model was compared to a one-factor model for the ALI. Interestingly, the one-factor produced better model fit, disproving Hypothesis 2 and suggesting that South African participants, at least those employed in the public health care sector, perceived AL as an overarching leadership style rather than one comprising the four constructs of which the concept is traditionally constituted.

Before the structural model of the research could be investigated it was important to establish whether AL could in fact be positioned as a job resource as per the JD-R model, the theoretical foundation of this article. Stander and Mostert (2013) hold that theoretical constructs of the same proposed theoretical grouping should be compared to each other in relation with the 'nomological network'. The nomological network describes a collection of theoretically corresponding concepts and denotes the interrelationship between these constructs (Westen \& Rosenthal, 2003). In this study, AL was compared to established job resources of communication and relationship with colleagues. Both these constructs have been proven as job resources in various studies and are measured through the VBBA questionnaire on experience and assessment of work, developed in the Netherlands (Van Veldhoven et al., 1997). AL did prove to fit within the nomological network when compared to these resources, proving Hypothesis 3 of this article and delineating that, as a leadership style, it can contribute to the perceived job resources public health care employees will perceive in their job role.

Hypotheses 4 through 6 were concerned with the structural model proposed in this research and investigated the predicting effect $\mathrm{AL}$ could have in the public health care sector, both on positive personal and work-related outcomes. Firstly, it was proposed that the AL leadership style would lead to higher levels of optimism amongst individual employees within the public health care sector. The rationale for this is found in the very essence of $\mathrm{AL}$, which is a leadership style that puts forward a number of empowering behaviours that generate a positive inclination with the individual that they will be able to effectively deal with stressors and be successful (Walumbwa et al., 2008). The implication of this is that AL could be utilised to promote optimism of employees in the public health care sector. It supports studies by Clapp-Smith et al. (2009), as well as Rego et al. (2012), who established that AL engendered the PsyCap constructs. It also supports the findings of Laschinger and Fida (2014) that AL and PsyCap have a positive impact on nurses' well-being. Hypothesis 5 proposed that AL would also lead to a positive work-related outcome, namely trust in the organisation. This was proven in this research. It is thus possible to argue that the organisational culture of authenticity and authentic behaviours exhibited by leaders who lead through AL will foster a greater level of trust amongst employees in the public health care sector (Bono \& Judge, 2003). This implies that a culture of AL will assist the public health care sector to develop a workforce that is willing to invest real energy and effort to achieve organisational goals, despite the substantial job demands that are associated with the sector (Bromiley \& Cummings, 1996).

Hypothesis 6 of this article provided an interesting perspective. Although the structural model proposed that AL would indirectly lead to work engagement through the mediating effects of both optimism and trust in the organisation, the authors were of view that a direct path between AL and work engagement would also exist in the public health care sector. This could not be conclusively proven. The authors argue that the very definition of AL must be considered here to explain this phenomenon. Luthans and Avolio (2003) delineate that AL requires both positive, authentic leadership capabilities and a positive, mature organisational culture. A possible explanation for the fact that AL was not directly promoting of work engagement is the consideration of how the public health care sector in South Africa currently looks as an environment and from a culture perspective. The Health Systems Trust (2011) describes this sector as significantly under-resourced. Von Holdt and Murphy (2006) comment that public health care employees work under severely stressful circumstances and George et al. (2013) describe the public health care working environment as one that is overburdening. Clearly, these descriptions are in stark contrast to the mature, positive organisational culture that constitutes a part of AL as described by Luthans and Avolio (2003). Hence, Hypotheses 
$7 \mathrm{a}$ and $7 \mathrm{~b}$ proved quite significant in the context of this study, as it is now possible to argue that AL will not promote work engagement in the public health care sector unless employees are inherently optimistic (Hypothesis 7a) or there exists a level of trust (Hypothesis $7 \mathrm{~b}$ ) within the organisation.

When the above was scrutinised through statistical analysis, both hypotheses were effectively proven. On an individual level, an optimistic individual will be able to translate a culture of AL within their organisation more effectively into a state of being engaged at work. The optimistic individual is inclined to be in a positive psychological state, receptive for development and will thus be engaged in a working environment that is characterised by AL (Luthans, Avolio, Avey \& Norman, 2007). Hypothesis 7a was thus proven. A significant indirect relationship between AL and work engagement through trust in the organisation was also proven in this research, thus rendering Hypothesis $7 \mathrm{~b}$ as accurate. It can thus be argued that the employee who has trust in the organisation will be more receptive for the culture provided through AL and be engaged in their job role. Thus, when the employees in the public health care sector believe that their employer has their best interest at heart, they will be more engaged to effectively deal with the highly demanding environment that is public health care services provision (Avolio, Gardner, Walumbwa, Luthans \& May, 2004).

\section{Practical implications}

The research reflected that the ALI can be utilised with scientific rigour and integrity in a South African sample and specifically in the South African public health care sector, a particularly under-resourced and burdensome workplace (George et al., 2013). This poses well for future studies in the sector in South Africa, as AL has been associated with a large number of positive outcomes in the health care environment internationally. This research revealed that adopting a leadership style of AL will assist the public health care sector to facilitate both positive personal and work-related outcomes. In the context of this study, AL was found to predict higher levels of optimism amongst individual employees. Thus, by incorporating an approach of $\mathrm{AL}$, the public health care sector could ensure individual employees will hold expectations of being successful in their endeavours in future. AL further proved to promote trust in the organisation amongst employees. When considering the above, this research suggests that efforts should be directed at promoting a culture of AL within the public health care sector and, further, interventions should be introduced that would assist the leadership fraternity of this sector to display behaviours associated with this leadership style. This will lead to both positive personal and work-related outcomes.

Interestingly, no direct path between $\mathrm{AL}$ and work engagement within the structural model could be conclusively proven. Only when optimism, on individual level, and trust in the organisation, on organisational level, were introduced was AL found to promote the levels of work engagement of employees in the public health care sector. This proved an intriguing part of this work and will lay the foundation for further exploration by the authors in future studies. At this stage, however, the explanation offered for this phenomenon is the fact that, for AL to be truly effective, an authentic individual leader as well as a conducive and mature workplace culture should be in place. This will enhance positive leader behaviours that will in turn develop employees. At this stage, as reflected in the literature, the South African public health care sector is full of challenges and is not one that can be described as a positive one that will actively promote levels of work engagement amongst employees. The authors believe, however, that this environment is highly unlikely to change in the near future, simply because of the immense demand for public health care services in the country that will continue to burden employees working in this sector (Blecher et al., 2011). This article therefore proposes interventions that could support quicker wins and facilitate a culture in which the clear value of $\mathrm{AL}$ could be more readily facilitated. In the context of this article, both optimism and trust in the organisation appeared to hold the properties that could translate AL to work engagement in the public health care sector. Hence, interventions should be introduced that promote these constructs. On an individual level, interventions that promote well-being must be considered to bolster the levels of optimism of employees. From an organisational perspective, enhanced trust in the organisation will assist in translating AL to a more engaged workforce. Possible interventions that will promote this are open communication, clearly articulating to employees in the public health care sector that their interests are important and to consider the direction in which the public health care sector is heading.

\section{Limitations and recommendations}

This study employed a cross-sectional design, which poses the potential risk of common method bias. However, Spector (2006) has proposed that this is a minor problem in research results. Chang, Van Witteloostuijn and Eden (2010) propose a number of approaches that could mitigate for common method bias, such as ensuring economic bottom line indicators are measured during empirical research (e.g. objective data such as performance and other applicable ratings) to relate to the subjective measurements via survey.

This study was also implemented across the entire public health care sector in all departments of the participating hospitals and clinics and included both clinical and nonclinical (support) staff. This was done intentionally as to gain a perspective of the overall sector. Future studies may benefit from a more focused approach, for example by studying the impact of the variables within a specific target group, such as nurses.

A comprehensive study across selected organisations in South Africa on the factor structure of the ALI can add value to leadership research. A comparative study will also be of value, in which the results of the public health care sector are compared to those of the private health care sector. This 
will substantiate the suggestion made by the authors in this article that it is the very environment of public health care in South Africa that influenced the variables and relationships in this study. Finally, future studies will benefit greatly by adopting a longitudinal approach to investigate whether the relationships revealed in this paper change over time and to investigate whether changes in the environment affect the results revealed here. For example, it would be interesting to investigate whether the structural paths between AL and work engagement change in the context of a public health care sector that is better resourced than is currently the case, that is, to investigate whether a mature, conducive working environment, which is a prerequisite for AL, will yield greater value for levels of engagement.

\section{Future research implications}

This research lays the foundation for further exploration of the effect of a culture of AL within public health care in South Africa. Firstly, the research suggested a thorough investigation of the maturity of the organisational culture of public health care as a whole as an important prerequisite for AL. Following this, this research can also stimulate a renewed focus on the potential of the PsyCap constructs as a facilitator of indirect effects between job resources and favourable outcomes. This calls for (1) a further exploration of the positioning of AL as a job resource within the JD-R model, a suggestion raised by this article and (2) a view of all the PsyCap constructs and their possible contribution to further leverage a culture of AL for positive organisational outcomes.

\section{Conclusion}

This article suggests the ALI can be used with scientific integrity in the South African context and specifically in the public health care sector. The article further suggests that the leadership style of AL will promote optimism and trust in the organisation and therefore provides evidence that the public health care sector should actively encourage, promote and develop this leadership style amongst its leadership and management fraternity. Lastly, the results of this article indicate that two quick-win strategies can be adopted to create a culture in which AL can be effectively translated into an engaged workforce. These strategies include interventions that promote authentic leader behaviour and optimism on an individual level and trust in the organisation.

\section{Acknowledgements Competing interests}

The authors declare that they have no financial or personal relationships that may have inappropriately influenced them in writing this article.

\section{Authors' contributions}

F.W.S. (North-West University) was the research project leader and corresponding author. L.T.d.B (North-West University) acted as statistical specialist and co-author.
M.W.S. (North-West University) acted in the capacity of subject matter expert and co-author.

\section{References}

Acosta, H., Salanova, M., \& Llorens, S. (2011). How organizational strategies predict team work engagement: The role of organizational trust. Ciencia \& Trabajo, 41 125-332.

Aryee, S., Budhwar, P., \& Chen, Z. (2002). Trust as a mediator of the relationship between organizational justice and work outcomes: Test of a social exchange model. Journal of Organizational Behavior, 23, 267-285. http://dx.doi. org/10.1002/job.138

Ashmore, J. (2013). 'Going private': A qualitative comparison of medical specialists' job satisfaction in the public and private sectors of South Africa. Human Resources for Health, 11(1), 1-12. http://dx.doi.org/10.1186/1478-4491-11-1

Avolio, B.J., Gardner, W.L., Walumbwa, F.O., Luthans, F., \& May, D.R. (2004). Unlocking the mask: A look at the process by which authentic leaders impact follower attitudes and behaviors. The Leadership Quarterly, 15, 801-823. http://dx.doi. org/10.1016/j.leaqua.2004.09.003

Bakker, A.B. (2011). An evidence-based model of work engagement. Current Directions in Psychological Science, 20(4), 265-269. http://dx.doi. org/10.1177/0963721411414534

Bakker, A.B., \& Demerouti, E. (2007). The job demands-resources model: State of the art. Journal of Managerial Psychology, 22, 309-328. http://dx.doi.org/10.1108/ 02683940710733115

Bakker, A.B., \& Demerouti, E. (2008). Towards a model of work engagement. Career Development International, 13(3), 209-223. http://dx.doi.org/10.1108/13620430 810870476

Bakker, A.B., Demerouti, E., Taris, T., Schaufeli, W.B., \& Schreurs, P. (2003). A multigroup analysis of the Job Demands-Resources model in four home care organizations. International Journal of Stress Management, 10, 16-38. http:// dx.doi.org/10.1037/1072-5245.10.1.16

Bamford, M., Wong, C., \& Laschinger, H. (2013). The influence of authentic leadership and areas of worklife on work engagement of registered nurses. Journal of Nursing Management, 21, 529-540. http://dx.doi.org/10.1111/j.1365-2834.2012.01399.x

Bass, B.M., \& Steidlmeier, P. (1999). Ethics, character, and authentic transformational leadership behavior. The Leadership Quarterly, 10(2), 181-217. http://dx.doi. org/10.1016/S1048-9843(99)00016-8

Blecher, M., Kollipara, A., DeJager, P., \& Zulu, N. (2011). Health financing. In A Padarath, \& R. English (Eds.), South African Health Review, 2011 (pp. 29-48). Durban: Health Systems Trust.

Bono, J.E., \& Judge, T.A. (2003). Self-concordance at work: Toward understanding the motivational effects of transformational leaders. Academy of Management Journal, 46, 554-571. http://dx.doi.org/10.2307/30040649

Bromiley, P., \& Cummings, L. (1996). Transaction costs in organizations with trust. In R. Bies, R. Lewicki, \& B. Sheppard (Eds.), Research on negotiation in organizations (pp. 219-247). Greenwich, CT: JAI.

Brown, C. (2014). Authentic leadership and the effects of trust and positive psychological capital on work engagement in SEC football. Paper delivered at the Clute Institute International Academic Conference, Orlando, Florida, 02 January.

Chang, S.J., Van Witteloostuijn, A. \& Eden, L. (2010). From the editors: Common method variance in international business research. Journal of Internationa Business Studies, 41(2), 178-184. http://dx.doi.org/10.1057/jibs.2009.88

Christian, C.S., \& Crisp, N. (2012). Management in the South African public health sector: An x-inefficiency perspective. Development Southern Africa, 29(5), 725737. http://dx.doi.org/10.1080/0376835X.2012.730972

Clapp-Smith R., Vogelgesang, G.R., \& Avey, J.B. (2009). Authentic leadership and positive psychological capital: The mediating role of trust at the group level of analysis. Journal of Leadership and Organizational Studies, 15, 227-240. http:// dx.doi.org/10.1177/1548051808326596

Cohen, J. (1988). Statistical power analysis for the behavioral sciences. (Rev. ed.). Orlando, FL: Academic Press.

Demerouti, E., Bakker, A.B., De Jonge, J., Janssen, P.P.M., \& Schaufeli, W.B. (2001). Burnout and engagement at work as a function of demands and control. Scandinavian Journal of Work Environment and Health, 27, 279-286. http:// dx.doi.org/10.5271/sjweh.615

Department of Health. (2011). National core standards for Health establishments in South Africa [Adobe Digital Editions Version]. Retrieved 2014, from http://www. rhap.org.za/wp-content/uploads/2014/05/National-Core-Standards-2011-1.pdf

Ferres, N., Connell, J., \& Travaglione, A. (2005). The effect of future redeployment on organization trust. Strategic Change, 14(2), 77-91. http://dx.doi.org/10.1002/ jsc.713

Ferres, N., \& Travaglione, T. (2003). The development and validation of the workplace trust survey (WTS): Combining qualitative and quantitative methodologies. Paper presented at APROS, Mexico, December.

Gardner, W.L., Avolio, B.J., Luthans, F., May, D.R., \& Walumbwa, F. (2005). Can you see the real me? A self-based model of authentic leader and follower development The Leadership Quarterly, 16, 343-372. http://dx.doi.org/10.1016/j. leaqua.2005.03.003

George, G., Atujuna, M., \& Gow, J. (2013). Migration of South African health workers: The extent to which financial considerations influence internal flows and external
movements. BMC Health Services Research, 13(1), 297-310. http://dx.doi. org/10.1186/1472-6963-13-297 
George, G., Gow, J., \& Bachoo, S. (2013). Understanding the factors influencing healthworker employment decisions in South Africa. Human Resources for Health, 10(1) worker employment decisions in South Africa. Human

Gilbert, J., \& Tang, T. (1998). An examination of organizational trust antecedents. Public Personnel Management, 27(3), 321-338.

Gillis, T. (2003). More than a social virtue: Public trust among organizations mos valuable asset. Communication World, 20(3), 10-12.

Gilson, L., \& Daire, J (2011). Leadership and governance within the South African health system. In A. Padarath, \& R. English (Eds.), SAHR (pp. 69-80). Durban: HST.

Görgens-Ekermans, G., \& Herbert, M. (2013). Psychological capital: Internal and external validity of the Psychological Capital Questionnaire (PCQ24) on a South African sample. South African Journal of Industrial Psychology, 39(2), 1-12. http://dx.doi.org/10.4102/sajip.v39i2.1131

Harrison, D. (2009). An overview of health and health care in South Africa 19942010: Priorities, progress and prospects for new gain. Discussion document commissioned by the Henry J. Kaiser Family Foundation to help inform the National Health Leaders' Retreat. Muldersdrift, South Africa, January.

Hassan, A., \& Ahmed, F. (2011). Authentic leadership, trust and work engagement. International Journal of Social, Business, Psychological, Human Science and Engineering, 5(8), 172-178.

Health Systems Trust. (2011). District Health Barometer Year 2011/12 [Adobe Digital Editions Version]. Retrieved 2014, from http://www.health-e.org.za/wp-content/ uploads/2013/04/DHB2011_12lowres.pdf

Health Systems Trust. (2013). South African Health Review 2012/2013 [Adobe Digital Editions Version]. Retrieved 2014, from http://www.health-e.org.za/wp-content/ uploads/2013/04/SAHR2012_13_lowres_1.pdf

Ilies, R., Morgeson, F., \& Nahrgang, J. (2005). Authentic leadership and eudaemonic wellbeing: Understanding leader-follower outcomes. The Leadership Quarterly, 16(3), 373-394. http://dx.doi.org/10.1016/j.leaqua.2005.03.002

Joseph, E., \& Winston, B. (2005). A correlation of servant leadership, leader trust, and organizational trust. Leadership and Organizational Development Journal, 26(1/2), 6-22. http://dx.doi.org/10.1108/01437730510575552

Kernis, M.H. (2003). Toward a conceptualization of optimal self-esteem. Psychological Inquiry, 14, 1-26. http://dx.doi.org/10.1207/S15327965PLI1401_01

Laschinger, H.K.S., \& Fida, R. (2014). New nurses burnout and workplace wellbeing: The influence of authentic leadership and psychological capital. Burnout Research, 1, 19-28. http://dx.doi.org/10.1016/j.burn.2014.03.002

Laschinger, H.K.S., Wong, C.A, \& Grau, A.L. (2013). Authentic leadership, empowerment and burnout: A comparison in new graduates and experienced nurses. Journal of Nursing Management, 21, 541-552. http://dx.doi.org/10.1111/ j.1365-2834.2012.01375.x

Leigh, J. (2013). Modelling suggests authentic leadership from managers influences structural empowerment, job satisfaction and self-rated performance amons nurses. Evidence Based Nursing, 17(2), 55-57. http://dx.doi.org/10.1136/eb2013-101424

Liang, X., \& Yang, Y. (2014). An evaluation of WLSMV and Bayesian methods for confirmatory factor analysis with categorical indicators. International Journal of Quantitative Research in Education, 2(1), 17-38. http://dx.doi.org/10.1504/ IJQRE.2014.060972

Luthans, F. (2002). The need for and meaning of positive organizational behavior Journal of Organizational Behavior, 23, 695-706. http://dx.doi.org/10.1002/ job.165

Luthans, F., \& Avolio, B.J. (2003). Authentic leadership: A positive developmental approach. In K.S. Cameron, J.E. Dutton, \& R.E. Quinn (Eds.), Positive organizationa scholarship (pp. 241-261). San Francisco, CA: Berrett-Koehler Publishers.

Luthans, F., Avolio, B.J., Avey, J.B., \& Norman, S.M. (2007). Positive psychological capital: Measurement and relationship with performance and satisfaction. Personnel Psychology, 60(3), 541-572. http://dx.doi.org/10.1111/j.17446570.2007.00083.x

Luthans, F., \& Youssef, C.M. (2004). Human, social, and now positive psychological capital management: Investing in People for Competitive Advantage. Organizational Dynamics, 33, 143-160. http://dx.doi.org/10.1016/j.orgdyn.2004.01.003

Luthans, F., Youssef, C.M., \& Avolio, B.J. (2007). Psychological capital. New York, NY: Oxford University Press.

Muthén, L.K., \& Muthén, B.O. (2014). Mplus user's guide. (7th edn.). Los Angeles, CA: Muthén \& Muthén.

Neider, L.L., \& Schriesheim, C.A. (2011). The Authentic Leadership Inventory (ALI) Development and empirical tests. The Leadership Quarterly, 22(6), 1041-1198. http://dx.doi.org/10.1016/j.leaqua.2011.09.008

Norman, S.M., Avolio, B.J., \& Luthans, F. (2010). The impact of positivity and transparency on trust in leaders and their perceived effectiveness. The Leadership Quarterly, 21, 350-364. http://dx.doi.org/10.1016/j.leaqua.2010.03.002

Paliszkiewicz, J., \& Koohang, A. (2013). Organizational trust as a foundation for knowledge sharing and its influence on organizational performance. The Online Journal of Applied Knowledge Management, 1(2), 116-127.

Peus, C., Wesche, J.S., Streicher, B., Braun, S., \& Frey, D. (2012). Authentic leadership: An empirical test of its antecedents, consequences, and mediating mechanisms. Journal of Business Ethics, 107, 331-348. http://dx.doi.org/10.1007/s10551-011 1042-3
Pillay, R. (2009). Retention strategies for professional nurses in South Africa. Leadership in Health Services, 2(1), 39-57. http://dx.doi.org/10.1108/17511870910928010

Rego, A. Sousa, F., Marques, S., \& Cunha, M.P. (2012). Authentic leadership promoting employees' psychological capital and creativity. Journal of Business Research, 65, 429-437. http://dx.doi.org/10.1016/j.jbusres.2011.10.003

Rhemtulla, M., Brosseau-Liard, P.É., \& Savalei, V. (2012). When can categorical variables be treated as continuous? A comparison of robust continuous and categorical SEM estimation methods under suboptimal conditions. Psychological Methods, 17(3), 354-373. http://dx.doi.org/10.1037/a0029315

Rucker, D.D., Preacher, K.J., Tormala, Z.L., \& Petty, R.E. (2011). Mediation analysis in social psychology: Current practices and new recommendations. Social and Personality Psychology Compass, 5(6), 359-371. http://dx.doi.org/10.1111/ j.1751-9004.2011.00355.x

Salkind, N.J. (2009). Exploring research. (7th edn.). Englewood Cliffs, NJ: Pearson Prentice.

Sanders, D., \& Chopra, M. (2006). Key challenges in attaining health in an inequitable society: The case of South Africa. American Journal of Public Health, 96(1), 73-78. $\mathrm{http}: / / \mathrm{dx}$.doi.org/10.2105/AJPH.2005.062679

Schaufeli, W.B., \& Bakker, A.B. (2004). Job demands, job resources, and their relationship with burnout and engagement: A multi-sample study. Journal of Organizational Behavior, 25, 293-315. http://dx.doi.org/10.1002/job.248

Schaufeli, W.B., Salanova, M., González-Romá, V., \& Bakker, A.B. (2002). The measurement of engagement and burnout: A two sample confirmatory factor analytic approach. Journal of Happiness Studies, 3, 71-92. http://dx.doi. org/10.1023/A:1015630930326

Sonnentag, S. (2003). Recovery, work engagement, and proactive behaviour: A new look at the interface between nonwork and work. Journal of Applied Psychology, 88(3), 518-528. http://dx.doi.org/10.1037/0021-9010.88.3.518

Spector, P.E. (2006). Method variance in organizational research: Truth or urban legend? Organizational Research Methods, 9(2), 221-232. http://dx.doi. org/10.1177/1094428105284955

Stander, F.W., \& Mostert, K. (2013). Assessing the organisational and individual strengths use and deficit improvement amongst sport coaches. South African Journal of Industrial Psychology, 39(2), 1-13. http://dx.doi.org/10.4102/sajip. v39i2.1160

Storm, K., \& Rothmann, S. (2003). A psychometric analysis of the Utrecht Work Engagement Scale in the South African police service. South African Journal of Industrial Psychology, 29, 62-70. http://dx.doi.org/10.4102/sajip.v29i4.129

Struwig, F.W., \& Stead, G.B. (2001). Planning, designing and reporting research. Cape Town: Pearson Education

Tims, M., Bakker, A.B., \& Xanthopoulou, D. (2011). Do transformational leader enhance their followers' daily work engagement? The Leadership Quarterly, 22, 121-131. http://dx.doi.org/10.1016/j.leaqua.2010.12.011

Van de Schoot, R., Lugtig, P., \& Hox, J. (2012). A checklist for testing measurement invariance. European Journal of Developmental Psychology, 9(4), 486-492. http:// dx.doi.org/10.1080/17405629.2012.686740

Van Veldhoven, M., Meijman, T.F., Broersen, J.P.J., \& Fortuin, R.J. (1997). Handleiding VBBA: Onderzoek naar de beleving van psychosociale arbeidsbelasting en werkstress met behulp van de vragenlijst beleving en beoordeling van de arbeid [Manual VBBA: Research on the experience of psychosocial workload and job stress by means of the questionnaire on the experience and Evaluation of work]. Amsterdam, The Netherlands: SKB.

Van Veldhoven, M., Meijman, T.F., Broersen, J.P.J., \& Fortuin, R.J. (2002). Handleiding VBBA. (2nd edn.). Amsterdam, The Netherlands: SKB.

Von Holdt, K., \& Murphy, M. (2006). Public hospitals in South Africa: Stressed institutions, disempowered management. In S. Buhlungu, J. Daniel, R. Southall, \& J. Lutchman (Eds.), State of the nation: South Africa 2007. Cape Town: HSRC Press.

Walumbwa, F.O., Avolio., B., Gardner, W., Wernsing, T., \& Peterson, S. (2008). Authentic leadership: Development and validation of a theory-based measure. Journal of Management, 34, 89-126. http://dx.doi.org/10.1177/0149206307308913

Walumbwa, F.O., Luthans, F., Avey, J.B., \& Oke, A. (2009). Retracted: Authentically leading groups: The mediating role of collective psychological capital and trust. Journal of Organizational Behavior, 32, 4-24. http://dx.doi.org/10.1002/job.653

Walumbwa, F.O., Wang, P., Wang, H., Schaubroeck, J., \& Avolio, B.J. (2010). Retracted: Psychological processes linking authentic leadership to follower behaviors. The Leadership Quarterly, 21, 901-914. http://dx.doi.org/10.1016/j. leaqua.2010.07.015

Wang, D.S., \& Hsieh, C.C. (2013). The effect of authentic leadership on employee trust and employee engagement. Social Behavior and Personality: An International Journal, 41(4), 613-624. http://dx.doi.org/10.2224/sbp.2013.41.4.613

Westen, D., \& Rosenthal, R. (2003). Quantifying construct validity: Two simple measures. Journal of Personality and Social Psychology, 84(3), 608-618. http:// dx.doi.org/10.1037/0022-3514.84.3.608

Wong, C.A., \& Cummings, G.G. (2009). The influence of authentic leadership behaviours on trust and work outcomes of health care staff. Journal of Leadership Studies, 3(2), 6-23. http://dx.doi.org/10.1002/jls.20104

Xanthopoulou, D., Bakker, A.B., Demerouti, E., \& Schaufeli, W.B. (2009). Reciprocal relationships between job resources, personal resources, and work engagement Journal of Vocational Behavior, 74, 253-244. http://dx.doi.org/10.1016/j jvb.2008.11.003 